in the north-east, South Africa possesses an almost fully developed tropicel East African aszociation. However, in South Africa this association is very definitely restricted to a small area. A well-marked southern 'boundary' is evident in the region of Lake St. Lucia, there being a most pronounced subtraction of tropical species in this region. The factors causing this southward limitation have still to be clarified. The cause of the western limitation of the tropical assemblage inland is explainable in terms of physiography, the ascent to the central plateau causing profound changes in climate; but there are no comparable physiographical changes in the St. Lucia region. There are also no abrupt zonal climatic changes in this region, although it seems significant that the $18^{\circ} \mathrm{C}$. mid-winter isotherm crosses the coastal plain in this region, after skirting the western edge of the Mozambique plain. This isotherm is used to divide a tropical from a non-tropical climate in Köppen's classification of climates ${ }^{2}$. Phytogeographical changes in this region are not in themselves sufficient to account for the general changes in the fauna, for although the taxonomic changes in the vegetation are extremely marked, the physiognomic characters of the various plant associations are not conspicuously altered.

Whatever the factors causing the biogeographical changes in Zululand may be, it is evident that the widely held belief that "There is a strong, general reduction of the (tropical) fauna northward into the Sahara and a less strong reduction and some differentiation southward into South Africa" is a serious under-estimation of the extensiveness and importance of these changes. The south-east African plant and animal communities are evidently built up from three quite distinct elements : a tropical complex entering from the north, a warm temperate complex entering from the south-west, and a relatively small complex indigenous to the area. The area clearly shows the characteristics of a transition zone, and this symposium brought into particular prominence the fundamental difference between the flora and fauna of the African tropics and the flora and fauna centred in the south-western Capo. The recognition of the south-western Cape as a biogeographical region distinct from the Ethiopian region is indicated by all the groups which are less recent than the contemporary birds and mammals, the members of which have the added advantage of homoiothermy. Birds and mammals traditionally form the zoogeographer's stock-in-trade ; but a proper assessment of the status of the southern temperate region of Africa is only possible if these groups are seen in $\mathbf{a}$ balanced perspective.

J. C. POYNTTON

${ }_{2}^{2}$ Poynton, J. C., S. Afr. J. Sci., 56, 307 (1960).

${ }^{3}$ Koppen, W., Grundriss der Klimakunde, second edit. (Walter de Gruyter and Co., Berlin, 1931).

${ }^{3}$ Darlington, P. J., Zoogeography : the Geographical Distribution of Animals, 433 (Wiley and Sons, New York, 1957).

\title{
HIGHER EDUCATION IN THE UNITED STATES
}

Diver R. J. B. CONANT has recently examined some of the ambiguities between school, college and university in the United States and compared the American approach to the university with that of certain European countries (Proc. Amer. Phil. Soc., 104, No. 6; December 15, 1960).

Conant believes that the comparison between the large numbers of American youth attending a college or university and the small numbers enrolled in European universities is misleading. A European university is essentially a collection of professional schools. If one compares the percentage of an agegroup attending universities in a European nation and those attending American postgraduate institutions, the difference is not very striking.

The road to the university in Europe does not pass through the equivalent of an American college. Instead, there are essentially pre-university schools for those who aim at university education. They offer a stiff academic course of eight or nine years in length centred on either : (a) Latin and Greok, or (b) Latin and a modern language (or two) and (c) moderm languages, science and mathematics. In each of the German States, and in each of the Swiss centons, there are three types of pre-university schools, each preparing students to pass examinations for a State certificate which, in turn, provides admission to a university anywhere in the country.

The American liberal arts college is in the nature of an accident. During the nineteenth century the programmes which were offered for the first degree in arts or science, or in letters, were expanded to include a number of practical subjects. This fact makes it difficult to explain to a European what is meant by an American college. Within a university, too, there is a great variety of four-year programmes of study which may be entered directly by highschool graduates.

An American college is possibly intermediate between a high school and a 'university' in the European sense of the word. For the most part, those who become lawyers now study three or four years in an undergraduate department of a university, or in a four-year liberal arts college before they enrol at a law school ; the same is true of medical students. On the other hand, engineering achools never became postgraduate schools. As a consequence, high-school graduates enter directly on their professional training if they want to become engineers. With so many complications in mind, it is hard to define without ambiguity the relation of a college to the education of members of the learned professions.

There is another ambiguity inherent in the American pattern of higher education. The standards of admission to the American colleges and universities are so varied as to make it impossible to describe them accurately.

Standards for the first degree are almost as diverse as the standards of admission; the mere holding of a bachelor's degree has almost no significance. Yet no one would publish a rank list of institutions or even be willing to be quoted publicly to the effect that a straight ' $A$ ' record in one college has about the same meaning as a ' $C$ ' record in another. In the United States, there is a hierarchy of institutions granting the first degree and a complete conspiracy of silence as to the existence of such a hierarchy.

On entrance tests, Conant recommends that leading professional schools of law and medicine and graduate 
schools of arts and sciences might require their candidates to pass a set of examinations which would demonstrate a mastery of academic subjects somewhat comparable to that required for entrance into a European university. The requirements might be as follows : a good resding, writing and sperking knowledge of at least one foreign language; a knowledge of mathematics as far as the calculus; a knowledge of physics, chemistry and biology at the freshman college-level; the ability to write a competent essay ; a knowledge of American history and political constitutions at a sophisticated level; and a knowledge of English and American literature at a corresponding level.

The variety of colleges prevents any uniform set of standards for admission. Therefore, the colleges could not, even if they desired, greatly influence the high-school curricula. But the relatively homogeneous nature of the graduate and professional schools makes the formulation of standards possible. The effect of this formulation would influence both colleges and high schools.

\title{
CIRRHOSIS OF THE LIVER IN FRANCE
}

A $\mathrm{N}$ investigation was recently undertaken by the nutrition department of the Institut national d'Hygiene, Paris, into the role of alcohol in the rtiology of cirrhosis of the liver in France (W.H.O. Chronicle, 14, December 1960).

Cirrhosis of the liver is relatively more common in France than in the rest of Europe; the death-rate in 1956 was the highest in Western Europe $(32.5$ per 100,000 inhabitants, as against $2 \cdot 6$ in England and Wales and 13.6 in the Federal Republic of Germany). For many years the medical profession in France has attributed the high incidence of the disease to the excessive consumption of alcohol, and statistics from hospitals agree that 80-85 per cent of cirrhoses are alcoholic in origin. But the medical profession has been accused of prejudice, and wine merchants have put forward the argument that in a population of whom 80 per' cent are drinkers, it could be maintained that practically all illnesses are alcoholic in origin.

The survey was designed to answer five questions : did persons believed to have cirrhosis of alcoholic origin drink more before their illness than random controls of the same age, same sex and same social environment without cirnhosis; were they less well nourished (that is, is cirrhosis due to alcohol or to an associated nutritional deficiency); is the reduced food intake so often seen when cirrhosis becomes decompensated a cause or a consequence of the decompensation; can the amount of alcohol that causes cirrhosis be determined; and what part does wine play in the alcoholism of cirrhotics?

The survey was carried out in hospitals in Paris, Marseilles, and Nantes, all patients with alcoholic cirrhosis being questioned and a non-cirrhotic control boing chosen at random in the same department for each patient questioned. The physical activity at work and outside work, the height and the usual weight before cirrhosis began were recorded, and a detailed food questionnaire was devised to establish the daily food intake before and after the onset of the disease, as well as the quantity of alcohol absorbed daily. In addition, questions were asked to reveal the social background about the patients' family and parents, income, living conditions and standard of living.

In all, 116 cirrhotics and 116 controls were compared. They did not differ significantly in age, physical activity, weight, or calorie or protein intake; but the alcohol intake of the cirrhotics was found to be approximately 2.5 times greater than that of the non-cirrhotics. Before they fell ill, the cirrhotics has been just as well nourished as the others ; consequently, it was concluded that cirrhosis cannot be attributed to dietary deficiencies.

Only one out of the 116 patients with cirrhosis said that he had consumed less than $80 \mathrm{gm}$. of alcohol (that is, less than 1 litre of wine at $10^{\circ}$ ) daily. From this it may be inferred that alcoholic cirrhosis appears only when consumption of alcohol is greater than 1 litre a day. But 50 out of the 116 controls consumed 80-160 gm. of alcohol a day (1-2 litres of wine), and it was only in the category from $160 \mathrm{gm}$. of alcohol (2 litres of wine) up that controls tended to decrease in number ( 7 out of 116), while more than half the cirrhotics (64 out of 116) came within this range.

It seems reasonable to infer that cirrhosis is likeliest when the intake is between 2 and 2.5 litres of wine a day (172-212 gm. of alcohol). Cirrhosis can occur when it is 1 litre or more, but when it exceeds 2 litres the probability of its occurrence is much increased.

Is decreased food intake a decompensating factor in cirrhosis ? Apparently not to any marked degree : in 88 cases out of the 116 it failed to cause decompensation; thus even at this late state the nutritional deficiency is only associated, not causal.

Finally, the survey established that wine represented 80-90 per cent of the alcohol ingested.

\section{ELECTROLYTIC JUNCTION WITH AMPLIFYING PROPERTIES}

\author{
By B. LOVREČEK and B. KUNST \\ Institute of Physical Chemistry, Technical Department, University of Zagreb
}

N previous papers 1,2 it has been shown that the
rectification of altermating electric current at a
junction of two electrolytes is possible. This is
analogous to the same effect at a junction of $n$ - and
$p$-type semiconductors. It is to be expected that other
effects in semiconductors, for example, the amplifi- cation of electric current, have analogies in electrolytes. The purpose of this article is to report that this has been achieved.

The electric eircuit is similar to that used with Ovitron amplifiers ${ }^{3}$. The essential difference between the Ovitron and the device reported in this article is 